Available online at_www.iponlinejournal.com

\title{
Socio-demographic profiling of cases of acute poisoning in patients admitted in emergency ward of S. N. medical college, Agra
}

\author{
Shailesh Kumar Gupta ${ }^{1}$, Ajay Agrawal ${ }^{2}$, Richa Gupta ${ }^{3 *}$, Vaibhav Sharma ${ }^{4}$ \\ ${ }^{1}$ Junior Resident, ${ }^{2}$ Professor and Head, ${ }^{3}$ Assistant Professor, ${ }^{4}$ Lecturer, Dept. of Forensic Medicine and Toxicology, Sarojini \\ Naidu Medical College, Agra, Uttar Pradesh, India
}

\begin{abstract}
Introduction: Poisoning is one of most common cause of mortality. In India 50000 deaths occurs due to poisoning every year.
\end{abstract}

Aim: To identify and compare the socio-demographical profile and outcome in poisoning patients presenting to the Emergency ward of S.N. Medical College, Agra.

Materials and Methods: The record-based cross-sectional study was conducted for a period of 1 year in the emergency wards. The demographic data, hospital admission variables and outcomes were collected from medico-legal records and bead-head-tickets of patients obtained from the hospital record section. Analysis was used to find the interaction between the socio-demographic and hospital admission variables in association with outcomes of poisoning.

Results: A total 27412 patients are admitted in emergency department of S. N. Medical College, Agra during period from January 2018 to December 2018, out of which for 5924 patients medico legal examination done. Out of them a total of 768 patients were admitted with acute poisoning. The mean of patient's age was 28.67 . Males $(64.2 \%)$ were dominant over Females $(35.8 \%)$. Incidents of poisoning were predominant in married (50\%), residing in urban region (51.5\%), belongs to middle (20-40yrs) age-group (66.7\%). Patients with mild symptoms were 38.54\%, 58.3\% moderate and severe symptoms $3.1 \%$. Majority of the patients recovered $(83.8 \%)$ whilst $2.8 \%$ died.

Conclusion: socio-demographical distribution of cases depends on various factors which can be used for reduction of incidences of poisoning cases by counselling and other interventions as most of poisoning cases occurs in middle age group married men residing in urban region may be due to domestic dispute, job related problems, financial losses etc.

Keywords: Poisoning, Sociodemographic profile, Agra, Uttar Pradesh.

\section{Introduction}

The Father of Modern Toxicology, Mathieu Orfila, also found the term suitable when writing the introductory chapter to his famous 1813 General Treatise of Toxicology, 'The name of poison is given any substance, which, taken inwardly, in a very small dose, or applied in any kind of manner to a living body, impairs health, or destroys life ${ }^{6}$

To simplify the study of toxic phenomena, chemical exposures are usually assigned to one of four categories. Firstly, an acute exposure features chemical intoxications occurring over $24 \mathrm{~h}$ or less. These types of exposures are encountered in hospital emergency room situations where clinical toxicologists must manage patients who have accidentally or deliberately ingested high doses of drugs or other substances.

A poison is any substance that on introduction into the living body or on bringing into contact with any part thereof will produce ill effects or death by its local or systemic action or both. In fact, every substance is theoretically capable of producing toxicity and every drug is potentially a poison when used erratically ${ }^{5}$

Everyday around the world, almost 700 people die from poisonings and for every person that dies, several thousands more are affected by poisoning. ${ }^{1,2}$ Poisoning is the fourth most common cause of death in India. ${ }^{3}$ It has been estimated that, in India five to six persons per

\footnotetext{
*Corresponding Author: Richa Gupta, Dept. of Forensic Medicine and Toxicology, Sarojini Naidu Medical College, Agra, Uttar Pradesh, India

Email: drrichag79@gmail.com

http://doi.org/10.18231/j.ijfmts.2019.018
} 
lakh of population die due to acute poisoning every year $^{4}$

1. Most of poisoning cases occur in developing countries. Trends of poisoning in western countries are different from agriculture dependent developing country like India. Even in India in recent studies in different area showed variation in trends.

2. Study conducted in Hadoti Region, Rajasthan between July 2009 to December 2011 showed middle aged male from rural area are predominantly affected from acute poisoning ${ }^{7}$

3. study conducted in SRMS-IMS, Bareilly between Jan 2010 to December 2012 showed male with middle age group predominance ${ }^{8}$

4. Study conducted in Bangalore between November 2016-April 2017 showed literate, married, female of urban region are predominantly affected from acute poisoning $^{9}$

5. These studies showed different trend due to difference in level of literacy, reason of poisoning due to their socio-cultural differences. That's why more studies are needed to be done in each area to know the socio-demographical trends in that particular area, so that effective steps could be taken to decrease the incidences.

\section{Materials and Methods}

\section{Study site and duration}

Present record-based cross-sectional study is conducted in Emergency ward of Sarojini Naidu Medical College, Agra, which is a tertiary care centre in that area, which is a referral centre for nearby districts of western u.p., m.p. as well as rajasthan.

Period of study 1 year from January 2018 to December 2018.

\section{Source of data}

All patients admitted in emergency ward were studied for the information regarding total hospital admissions with number of patients cured, expired or absconded, for all leading unnatural causes of morbidity and mortality using Bead head tickets and medico-legal records obtained by Hospital Record section. From these records cases admitted due to acute poisoning including insect bite / snake bite is segregated for detailed study. All other medico-legal cases like physical assault, road traffic accident, Gunshot injuries, hanging, strangulations, and burn are excluded.

Data related to name, age, sex, religion, marital status, place of residence, type of poison ingested, severity of condition of patient at time of admission, mortality of patient was collected from records.

Severity of Condition of patient is recorded from bead head tickets which is obtained using Glasgow coma scale, in which score above 14 considered as average, 12-8 considered as poor and 7-3 considered as very poor.

All data was documented and statistically analysed to know the current trends of poisoning in the region.

Severity of Condition of patient is recorded from bead head tickets which is obtained using Glasgow coma scale, in which score considered as average, considered as poor and considered as very poor.

All data is documented and transcribed into a database created using Microsoft excel

\section{Glasgow coma scale}

Table

\begin{tabular}{|l|l|c|}
\hline \multicolumn{1}{|c|}{ Feature } & \multicolumn{1}{|c|}{ Response } & Score \\
\hline Best eye response & Open spontaneously & 4 \\
\cline { 2 - 3 } & Open to verbal command & 3 \\
\cline { 2 - 3 } & Open to pain & 2 \\
\cline { 2 - 3 } response & No eye opening & 1 \\
\hline \multirow{5}{*}{$\begin{array}{l}\text { Best motor } \\
\text { response }\end{array}$} & Oriented & 5 \\
\cline { 2 - 3 } & Confused & 4 \\
\cline { 2 - 3 } & Inappropriate words & 3 \\
\cline { 2 - 3 } & Incomprehensible sounds & 2 \\
\cline { 2 - 3 } & No verbal response & 1 \\
\hline \multirow{5}{*}{ Best verbal } & Obeys command & 6 \\
\cline { 2 - 3 } & Localizing pain & 5 \\
\cline { 2 - 3 } & Withdrawal from pain & 4 \\
\cline { 2 - 3 } & Flexion to the pain & 3 \\
\cline { 2 - 3 } & Extension to the pain & 2 \\
\cline { 2 - 3 } & No motor response & 1 \\
\hline
\end{tabular}

Analysis was used to find the interaction between the socio-demographic and hospital admission variables in association with outcomes of poisoning. Analysis done using average, percentage and ratio which is represented as bar diagrams and pie chart. 


\section{Observations and Results}

Out of A total 27412 patients are admitted in emergency department of S. N. Medical College, Agra during period from January 2018 to December 2018. Out of which for 5924 patients medico-legal examination done. Out of them a total of 768 patients were admitted with acute poisoning including snake bite and unknown insect bite. Rest of medico-legal cases are of physical assault, road traffic accident, burn, hanging etc. are excluded.

Out of total 768 patients of acute poisoning, 63 patients are bought by police or others as unknown patients (as destitute), for whom incomplete sociodemographic details are available. Out of 768 patients total $153(19.9 \%)$ patients belongs to < 20yrs age group, 513(66.7\%) belongs to 21-40yrs, 117(15.2\%) belongs to 41-60 years, while 1 patient belongs to > $60 y$ rs (Table 1). The mean of patient's age was 28.67 years. Out of 768 patients $493(64.2 \%)$ patients were male while $275(35.8 \%$ ) were female (Table 2) showing male predominance in acute poisoning cases. While on further analysis (Table 3) 0-20yrs age group showed female predominance with male-female ratio of $(0.55: 1)$, while in age group of $21-40 \mathrm{yrs}$ and 41 90yrs shows male predominance with male-female ratio of (2.44:1) \& (3.08:1). On analysis of marital status of patients (Table 4) affected population was found to be predominantly married 384(50\%), while $265(34.5 \%)$ were married although marital status of $119(15.4 \%)$.

Out of 768 patients $395(51.4 \%)$ patients belongs to urban area, $278(36.2 \%)$ to rural area, $32(4.1 \%)$ of semi urban area while 63 patients were of unknown (Table 5).

On the basis of history of poisonous substance (Table 6) most of patients unable to give clear history of poison $564(73.4 \%)$ while cases of snake bite is 108(14\%), Alcohol intoxication 49(6.3\%), Corrosive 9(1.1\%), Acid 8(), Celphos 7, Dhatura 7, Rat poison 6, Insecticide 5, Dye 3, Insect bite 3.

Out of 768 patients $296(38.5 \%)$ patients admitted with average condition (GCS Score >14), 448(58.3\%) Patients with poor condition (GCS Score 7-14) while $24(3.1 \%)$ patients with very poor condition (GCS Score 3-7) (Table 7). After treatment of patients 644(83.8\%) patients recovered and discharged satisfactorily, 22(2.8\%) patients died during treatment, while $105(13.6 \%)$ patients left against medical advice (LAMA)(Fig. 1).

Table 1: Age group of patients

\begin{tabular}{|c|c|c|c|}
\hline Age Group & $\mathbf{0 - 2 0}$ yrs. & $\mathbf{2 1 - 4 0}$ yrs. & $\mathbf{4 1 - 6 0}$ yrs. \\
\hline No. of patients & 153 & 513 & 118 \\
\hline
\end{tabular}

Table 2: Sex wise distribution of patients

\begin{tabular}{|c|c|}
\hline Sex & No. of patients \\
\hline Male & 493 \\
\hline Female & 275 \\
\hline
\end{tabular}

Table 3: Age and sexwise distribtion of patients

\begin{tabular}{|c|c|c|c|}
\hline & Male & Female & Ratio \\
\hline 0 -20 Years & 55 & 100 & $0.55: 1$ \\
\hline 20-40 Years & 364 & 149 & $2.44: 1$ \\
\hline$>$ 40 Years & 74 & 24 & $3.08: 1$ \\
\hline Total & 493 & 275 & $1.79: 1$ \\
\hline
\end{tabular}

Table 4: Marital status in poisoning cases

\begin{tabular}{|c|c|}
\hline Marital status & No. of patients \\
\hline Married & 384 \\
\hline Unmarried & 265 \\
\hline Unknown & 119 \\
\hline
\end{tabular}

Table 5: Residence of patients

\begin{tabular}{|c|c|c|c|c|}
\hline Residence & Urban & Rural & Unknown & $\begin{array}{c}\text { Semi- } \\
\text { urban }\end{array}$ \\
\hline $\begin{array}{c}\text { No. of } \\
\text { patient }\end{array}$ & 395 & 278 & 63 & 32 \\
\hline
\end{tabular}

Table 6: Type of accute poisoning

\begin{tabular}{|c|c|}
\hline Type of poison & Number of patients \\
\hline Snake bite & 108 \\
\hline Alcohal & 47 \\
\hline Corrosive & 9 \\
\hline Acid & 8 \\
\hline Celphos & 7 \\
\hline Dhatura & 7 \\
\hline Rat poison & 6 \\
\hline Insect bite & 4 \\
\hline Dye & 3 \\
\hline Insecticide & 5 \\
\hline Unknown & 564 \\
\hline
\end{tabular}


Table 7: Condition of patients during admission

\begin{tabular}{|c|c|c|c|}
\hline $\begin{array}{c}\text { Severity of } \\
\text { patients }\end{array}$ & $\begin{array}{c}\text { Average } \\
(\text { GCS }>\text { 14) }\end{array}$ & $\begin{array}{c}\text { Poor (GCS } \\
\text { 14-7) }\end{array}$ & $\begin{array}{c}\text { Very poor } \\
\text { (GCS 3-7) }\end{array}$ \\
\hline & 296 & 448 & 24 \\
\hline
\end{tabular}

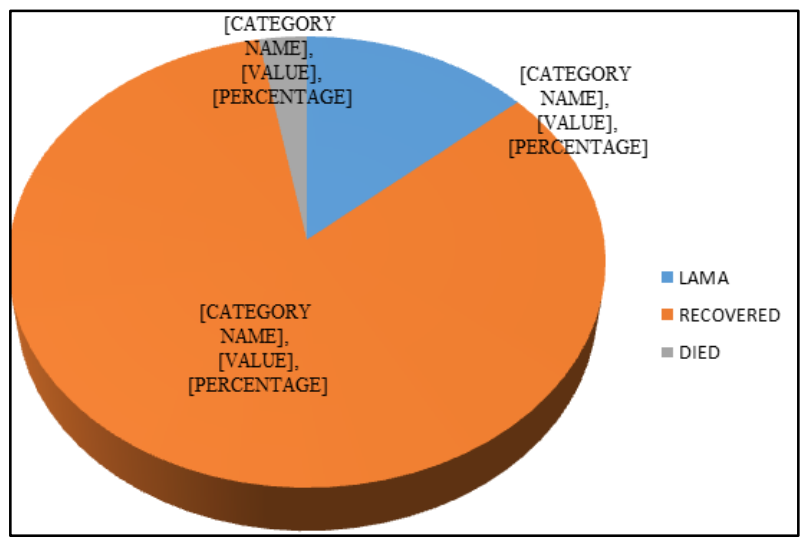

Fig. 1: Patient at discharge

\section{Conclusion}

Our study showed that poisoning cases in male population are more with high incidence rate in middle age group. Although in younger age group female predominance is found. So we need to do further study for causes of poisoning in young females and middle aged males so that necessary preventive steps can be taken to reduce incidences. In our study it was found that most of the cases are admitted with moderate symptoms, in which most of them survived, although a few deaths also occurred during treatment. In our study it was found that most of patients and their relatives are unable to give proper history regarding nature of poison, followed by snakebite and alcohol intoxication.

We needed to do improve history taking from patient and their relative or do toxicological analysis of samples so that exact cause of poisoning can be known which can help in the treatment process. Although on communication with patient's relative it was found that they weren't aware regarding importance of telling nature of exact poisons in process of treatment, although we are unable to prove that due to lack of data. We are needed to do a prospective study for causes and nature of poisoning (accidental/homicidal/suicidal) with a preformed proforma for poisoning cases. Awareness campaign is needed for people to make them aware regarding dangers of poisoning.

\section{Source of Funding}

None.

\section{Conflict of Interest}

None.

\section{References}

1. Zine KU, Mohanty AC. Pattern of acute poisoning at Indira Gandhi Medical College and Hospital, Nagpur. J Ind Aca For Med 1998;20:37-9.

2. World Health Organisation. Guidelines for poison control. Bulletin 1999; Geneva, World Health Org.

3. Unikrishnan B, Singh B, Rajeev A. Trends of acute poisoning in south Karnataka. Katmandu Univ Med $J$ 2005;3(2):149-54

4. Narayana Reddy K S. Toxicology, General consideration. In: Narayana Reddy K S. Essentials Forensic Med Toxicol 2010;446-65.

5. Krishna vij $5^{\text {th }}$ edition ( p. 439)

6. P.C. Burcham. Core Concepts in Toxicology. Introduction Toxicology 2013;30-33.

7. Surendra Khosya, SR Meena, Current Trends of Poisoning: An Experience at a Tertiary Care Hospital Hadoti Region, Rajasthan, India, J Clin Toxicol 2016;6(2):1

8. Jaswinder Singh, Jaspreet Kaur, ,Trends of Poisoning in a Tertiary Care Centre of North West Uttar Pradesh , J Indian Acad Forensic Med. October-December 2015;37(4):396.

9. Sathvika reddey, Devi revathi, sociodemographic profile of patients with acute poisoning in the emergency wards of a tertiary care hospital, Int J Pharm Pharma Sci 10(6):50.

How to cite this article: Gupta SK, Agrawal A, Gupta R, Sharma V. Socio-demographic profiling of cases of acute poisoning in patients admitted in emergency ward of S. N. medical college, Agra. Int J Forensic Med Toxicol Sci 2019;4(3):82-5. 